\title{
THE PROSPECTS OF REVIVAL OF RIVER NAVIGATION IN UKRAINE
}

\section{ПЕРСПЕКТИВЫ ВОЗРОЖДЕНИЯ РЕЧНОГО СУДОХОДСТВА В УКРАИНЕ}

\author{
Y.Yarmolovich, $P h D$, associate professor \\ Ю.Р. Ярмолович, , к.т.н., доцент \\ National University "Odessa Maritime Academy” \\ Национальный университет «Одесская морская академия»
}

\begin{abstract}
The article investigates main actual problems of Ukrainian river shipping. For the moment the minor part of country cargoes are transporting via inner water ways. There is only $15-20 \%$ of rivers potential in use nowadays. At the same time the scope of companies are seeking possibilities to be involved into the river shipping due to less costs involved. Shipped cargoes analysis eliminated the group of most used of them. There are grain, steel and ore. The minor part includes building materials and containerized cargoes. We have evaluated present situation of river infrastructure ports, terminals, locks, navigation support, fleet, canals. Most of components are in unsatisfactory condition and needs modernization. Ports and terminals are equipped with worn out equipment. Most of locks are old and their capacity is limited and insufficient. Navigation equipment is outdated; some of buoys and lights are lost. Most expensive object of the inner water ways are canals, most complicated procedure is canals maintaining. They weren't dredged till requested draft. Such dredging to be arranged for $80 \%$ of navigable rivers. Resources amount to be involved is huge and could be accumulated under government supervision only. Besides, legal system is rather improper. It proclaims national business priority. "Old" rules give no chance to attract foreign investors and use foreign flag fleet. Custom arrangement is complicated and expensive. Ukrainian government is discussing modern "River Low" a long time but it doesn't finalized yet. There are several companies responsible for each component of water way usage fees collecting. It is important to concentrate funds and coordinate efforts in the one hand.

Conclusions which are proposed in the article are:

- Ukrainian inner water ways actual condition satisfies present balance between cargo supply and demand

- further progress is difficult without funds and resources concentration likely under government supervision

- the benefits for river shipping expansion to be evaluated in consideration of social and ecological aspects.
\end{abstract}

Keywords: river transport, inland waterways, river tax, unification of rules. 


\section{РЕФЕРАТ}

Стаття стосується питань стану річкового транспорту в Україні та методів його відродження. Станом на сьогодні річковий потенціал використовується частково, навіть у порівнянні 3 радянськім минулим, що призводить до зниження потенціальних надходжень до бюджету. Згідно 3 даними, які наведено в публікаціях багатьох авторів, значна кількість приватних та державних компаній виявляе зацікавленість в збільшенні обсягів річкових перевезень. Проведено оцінювання вантажної бази перевезення - зернових, мінеральних, будівельних, рудних вантажів, контейнерів. Виявлено, що найбільшу зацікавленість виявляють зернотрейдери та металургійні комбінати. Проаналізовано сучасний стан інфраструктури річкового транспорту - портів, терміналів, та шлюзів, кількість тоннажу, навігаційного забезпечення, наявність глибин. Більшість складових, які забезпечують ефективність річкових перевезень знаходяться у незадовільному стані та потребують глибокої модернізації. Найбільш довгостроковою та затратною складовою виявляється забезпечення глибин. Стан навігаційного обладнання, шлюзів, портів та терміналів також не є задовільним. Законодавча база річкових перевезень досі має значні недоліки, які обмежують можливість залучення іноземних інвесторів. Діючі митні нормативи ускладнюють та здорожують митне оформлення вантажів. Закон про річкові перевезення дискутується довгий час та досі не прийнятий. В статі надано перелік установ, відповідальних за збирання платежів по кожній складовий річкового комплексу. Висвітлено переваги централізованого збирання та використовування коштів, об'єднання зусиль різних установ в єдиному напрямі. Проаналізовано стан, кількісний та якісний склад річкового флоту України.

У висновках визначається, що сучасний стан галузі дозволяє задовольнити потреби наявної вантажної бази. Подальший розвиток галузі можливий у разі комплексного підходу до використання річкового потенціалу держави, урахуванні соціальних та екологічних аспектів.

Дискуссии на тему восстановления объемов речного судоходства в Украине идут со времени становления независимой Украины. Водный транспорт имеет ряд преимуществ по сравнению с остальными видами транспорта: экологичность (в 5 раз чище железнодорожного и в 10 раз чище автомобильного), низкую стоимость перевозки, (потребляется в 3-4 раза меньше топлива чем при железнодорожных перевозках), гарантии высокой сохранности груза [1]. Кроме того, использование внутренних водных путей снижает нагрузку на автотрассы и железные дороги, приводит к развитию инфраструктуры, росту количества рабочих мест. Активное использование речного транспорта в Украине приведет к интенсификации торговых отношений со странами ЕС, Польшей, прибалтийским регионом, республикой Беларусь.

Ключові слова: річковий транспорт, внутрішні водні шляхи, річковий податок, уніфікація правил. 
Постановка проблемы в общем виде и ее связь с важными научными или практическими задачами

В настоящее время водный потенциал страны включает три крупные судоходные реки: Дунай, Днепр и Южный Буг. Кроме того, возможно использование ряда малых рек, таких как Припять, Десна, Северский Донец, Ворскла, Днестр, Горынь, Стырь, Самара, Псел. Протяженность судоходных рек Украины в 2000 годы оценивавшееся в более чем 4000 км., в настоящее время снизилось до 1400 км. Направление течения рек совпадает с основным направлением перемещения грузов - с континентальной части страны к Черному морю и обратно. Несмотря на высокий потенциал и частично сохранившуюся инфраструктуру, фактически задействована примерно десятая часть потенциала водных ресурсов. Так, в 2018 году по Днепру было перевезено по различным сведениям от 6 до 8 млн. тонн грузов, по Южному Бугу до 0,5 млн. тонн. При этом специалисты оценивают годовой потенциал Днепра в 30 млн. тонн а всех водных путей Украины в целом от 60 до 100 млн. тонн в год. По состоянию на 2017 год доля грузов, перевезенных речным транспортом внутри страны составляла около 0,4 - 0,5 \%, в странах Евросоюза этот же показатель достигает 7\% [2].

Максимальный объем использования внутренних водных путей приходится на 80 годы 20 века. На пике развития показатели перевезенных грузов достигали 45 млн. тонн. В течение 295 дней навигации 1976 года только днепровскими шлюзами прошло около 71 тыс. судов. В судоходстве было задействовано 17 рек, длина обслуживаемых водных путей составляла более 5000 км, было установлено и поддерживалось в рабочем состоянии до 11 тыс. навигационных знаков. Переломным моментом явился 1991 год, год распада Советского Союза. К 2016 году общая длина судоходных рек Украины уменьшилась в 3 раза, значительно снизилось техническое состояние шлюзов, серьезно ухудшилась навигационная обстановка на реках [3].

Анализ последних достижений и публикаций, В которых начато решение данной проблемы и выделение нерешенных ранее частей общей проблемы

Анализ возможностей использования внутренних водных путей Украины и перспективы создания условий для возрождения речного судоходства рассматривались рядом авторов в течение всего периода независимости Украины. Большое количество публикаций в изданиях «Порты Украины», «Моряк Украины», «Работник моря», интернет изданиях «Seafarers journal», «Морское обозрение», «Центр транспортных стратегий» постоянно публикуют статьи, посвященные возможности увеличения использования водных путей, способы реализации этой задачи. Свое мнение по поводу направления развития и точек приложения усилий активно высказывают руководители предприятий ГП «Укрводшлях», ПАО «Укргидроэнерго», АСК «УДП», ОАО СП «НИБУЛОН», зам. Министра инфраструктуры Украины. В последние годы произошли изменения, требующие выработки новых рекомендаций, отвечающих современным вызовам и сложившимся в стране обстоятельствам. 
Грузовую базу перевозок внутренними водными путями Украины составляют зерновые, строительные грузы, черные металлы, стройматериалы, железорудное сырье, контейнера. Основные заказчики - зернотрейдеры, металлургические комбинаты, строительные компании.

В настоящее время во внутренних речных перевозках задействовано ограниченное количество компаний. Основные объемы осваиваются несколькими национальными игроками, среди которых основную нагрузку несут акционерная компания «Украинское Дунайское пароходство» (УДП), которое управляет более чем 300 самоходными и несамоходными судами, ООО «Укрричфлот» - около 90 судов, ООО СП «НИБУЛОН» - 48 судов, «Гермес Трейдинг» - 5 судов. «НИБУЛОН» концентрирует свои усилия на Днепре и Южном Буге, «Укрричфлот» на Дунае и Днепре. УДП в основном на Дунае, «Гермес Трейдинг» на Южном Буге.

\section{Формулирование целей статьи (постановка задач)}

Целью исследования является анализ современного состояния внутренних водных путей Украины, предложений по изменению законодательной базы, возможности использовать зарубежный опыт. Достижение цели диктует необходимость оценки возможностей привлечения зарубежных и национальных инвесторов, состояния флота, гидротехнических сооружений, принципов тарификации и ценообразования.

\section{Изложение материала, исследования с обоснованием полученных результатов}

Для возрождения речного судоходства необходимо решить ряд вопросов, среди которых наиболее значимые следующие:

1. Дноуглубление.

В настоящее время обеспечение заявленных глубин гарантируется только в нижнем течении Днепра, до г. Днепр. Специфика речного судоходства постоянные дноуглубительные работы, сложные, дорогостоящие, требующие привлечения высококлассных специалистов - гидрологов, взрывотехников, экологов. Река переносит огромное количество взвешенных частиц, оседание которых приводит к заиливанию, проходные глубины уменьшаются, их поддержание требует содержания значительного количества дорогостоящих судов специального назначения - земснарядов, землесосов, драг, грунтоотвозных шаланд, промерных судов. Без постоянной очистки реки мелеют, заиливаются, берега зарастают камышом, фарватеры теряют заявленные глубины. Для поддержания водного баланса необходимо заниматься не только судоходными реками, но и их притоками, чтобы сохранить уровень и глубины. В настоящее время дноуглублением на реках должно заниматься государство в лице ГП «Укрводшлях». Администрация морских портов Украины (АМПУ) с 2017 года включилась в работы в качестве заказчика, создав новое отделение «Дноуглубительный флот», выделив средства и проведя тендеры на сумму около 300 млн. гривен [4]. ООО «НИБУЛОН» самостоятельно проводит дноуглубительные работы в акватории 
принадлежащих ему терминалов и на подходных путях на реках Днепр и Южный Буг. Цель - добиться заявленных глубин 3,65 м на всем протяжении реки Днепр, на первом этапе в среднем течении, до г. Киев, затем до Беларуси и в перспективе выйти к рекам Европы.

2. Тарификация и ценообразование.

Определенную проблему представляет несовершенная система начисления и взимания платы за использование водных путей. В настоящий момент взимаются оплата за пользование шлюзами, разведение мостов, лоцманскую проводку, портовые сборы, канальный сбор, санитарный сбор, корабельный сбор, плата за водопользование, экологические сборы, плата за транзитный проход акваторией порта, различного вида разовые разрешения. Суммарные затраты превышают стоимость перевозки железнодорожным транспортом с учетом действующих тарифов. Система начисления плат громоздка, сами платы взимаются несколькими ведомствами: разведение мостов - железной дорогой, пользование шлюзами - ГП «Укрводшлях», навигационное оборудование - ГП «Госгидрография», лоцманская проводка - ГП «Дельта лоцман». Изменения в порядке начисления и взимания сборов назрели и обсуждаются с 2005 года. Основная идея - взимать единый «речной» сбор, поступающий в распоряжение специально созданной госструктуры - Ассоциации речных портов Украины. Такая практика отвечает выполнению задачи по гармонизации с европейскими нормами в сфере ценообразования в рамках евроинтеграции. К сожалению, методика начисления сбора не разработана и еще даже не обсуждается. Судя по длительности обсуждения и обоснования модернизированных ставок портовых сборов, количеству доработок, единый «речной» сбор вступит в действие нескоро. На настоящем этапе в проекте закона о внутренних водных путях предусматривается переходной период сроком в два года [5].

3. Законодательная база.

С 2015 года проект «Закона о внутренних водных путях Украины» обсуждается Верховной Радой Украины. Основные положения проекта разрабатывались с 2013 года. Такое длительное время прохождения всех инстанций без конкретного результата говорит о разнонаправленной заинтересованности участников рынка морских перевозок [6]. Ряд положений, изменение которых давно назрело, вопросов не вызывает. Так, например, для организации международных контейнерных перевозок по внутренним рекам необходимы изменения таможенных правил. В настоящее время, в отличие от автотранспорта и железнодорожных перевозок отправка контейнеров в режиме «под таможенным контролем» по реке не предусмотрена. Досмотр на границе сопряжен с выгрузкой контейнеров, что приводит к дополнительным расходам, потере времени, простою флота.

Все участники обсуждения проекта закона согласны с тем, что порядок начисления и взимания платы за пользование внутренними водными путями должен быть упрощен и унифицирован. Камень преткновения - величина сборов и организация, курирующая их распределение. Предлагаемая привязка тарифа к пройденному расстоянию и количеству грузов вопросов не вызывает, 
а вот сам тариф кажется завышенным, предполагается, что его применение приведет к повышению дисбурсментов, особенно при перевозках на дальние расстояния. Рациональным выглядит предложение назначить переходный период для апробации новых тарифов с возможностью их доработки. Наиболее горячая дискуссия происходит по поводу допуска на рынок судов под иностранным флагом. В настоящее время таковые заходят в наши реки после подачи заявки и рассмотрения ее в течение 10 дневного срока. Фактически, применяется политика протекционизма, играющая на руку украинским судовладельцам, оперирующим флотом под национальным флагом. Понятно, что интеграция в европейское экономическое пространство с такой политикой невозможна. Против нее выступают компании-операторы судов под иностранными флагами, за - национальные перевозчики. В настоящее время часть сборов за пользование реками включена в стоимость судового топлива. Суда под иностранными флагами, бункерующиеся вне территории Украины денег в бюджет не принесут, их экипажи не заплатят налоги нашей стране. Двойные тарифы (национальный и иностранный флаг), если таковые будут применяться, вызовут негативную реакцию западных партнеров. Еще один спорный вопрос - создание единого координационного центра, отвечающего за управление, сбор, распределение и использование средств на внутренних водных путях, предположительно - «Администрации внутренних водных путей Украины» по образцу АМПУ. Во всех европейских странах использование внутренних водных путей является не только коммерческим, но и социальным проектом при значительной доле финансового участия государства. Частные структуры в нашей стране испытывают определенное недоверие к госструктурам в части справедливости распределения средств и рациональном их использовании. В качестве альтернатив предлагается создание акционерных обществ, ассоциаций, делегирование им прав контролировать финансовые потоки и утверждать их целевое назначение.

4. Шлюзы.

Одним из узких и проблемных мест в организации речного судоходства является состояние шлюзов. На Днепре в настоящее время функционируют и занимаются пропуском судов 6 шлюзов, находящихся в ведении ГП «Укрводшлях»: Киевский, Каневский, Кременчугский, Днепродзержинский, Запорожский район гидросооружений (ЗРГС) и Каховский [7]. Все они были сооружены в советское время, самый старый запущен в эксплуатацию 70 лет назад, последний серьезный ремонт производился более 10 лет назад. Практически на каждом требуется модернизация и замена узлов различной степени сложности. Из-за несвоевременных ремонтов, устаревшей конструкции и плохого технического состояния затраты на их содержание и использование высоки. По этим же причинам с 2012 года работает специальная техническая лаборатория, в обязанности которой входит ежедневный анализ состояния шлюзов, составление отчетов о возможности их эксплуатации. Каждые три месяца Регистр судоходства осуществляет технические надзоры для принятия решения о возможности дальнейшего безопасного их использования. 
Нарекания вызывают длительное время шлюзования, устаревшие нормативы (разрешено шлюзовать по одному несамоходному судну - отсюда двойная оплата и двойные затраты времени) [8], [9].

5. Флот.

В настоящее время речной флот Украины в значительной мере устарел морально и физически. Доля судов старше 20 лет составляет до 90 процентов транспортного флота. По сравнению с 1990 годом количество малотоннажных судов речного флота сократилось до 22\% прежнего состава и составляет около 630 судов общей грузоподъемностью до 900 тыс. т. Крупнейшие судовладельцы это АСК «Укрречфлот», ОАО «Украинское Дунайское пароходство», ООО «Столичная судоходная компания» и ООО СП «НИБУЛОН». Специалисты отмечают, что современный флот может освоить грузопотоки до 10-12 млн. т в год. Использование старого флота в международных перевозках проблематично. Возможный рост грузоперевозок внутренними водными путями потребует привлечения дополнительных ресурсов. На начальном этапе возможно оперирование судами иностранных судовладельцев. С учетом упадка судостроительной отрасли Украины быстрое пополнение флота возможно за счет покупки судов у иностранных верфей, хотя такая ситуация не лучший вариант для национальной экономики [10], [11]. При строительстве нового флота должны учитываться ряд ограничений, таких как запрет на сброс очищенных сточных вод с судов и ограничения по ветроволновому режиму на днепровских водохранилищах. Сейчас $90 \%$ судов под иностранным флагом не могут быть допущены на реки исходя из этих ограничений. Необходимо либо снизить требования национального законодательства, либо разрабатывать специальные режимы плавания для них.

Некоторые вопросы кажутся второстепенными, но без них восстановление речного судоходства в стране невозможно. Знаки навигационной обстановки были установлены в 50-х годах пришлого века и устарели. Часть можно отремонтировать и эксплуатировать далее, часть надо менять. Ответственность за их обслуживание в настоящее время возложена на ГП «Госгидрография». Речная информационная система работает с 2012 года, но в сферу ее покрытия входит только реки Дунай и Днепр. Требуется установка дополнительных станций, снимающих информацию о состоянии рек и передающих ее в единый центр в автоматическом режиме.

За время застоя речной отрасли необходимость в квалифицированных специалистах значительно снизилась. Старые кадры выбывали по возрасту, потребность в поддержании прежнего количества штатных сотрудников отсутствовала. При увеличении объемов перевозок прогнозируется «кадровый голод», особенно в условиях ослабленной национальной экономики и несоответствии зарплат европейскому уровню.

Речная портовая инфраструктура также включает 10 речных портов и до 50 терминалов, сориентированных на перевалку зерновых грузов, металлопроката, руд, минерально - строительных грузов. Порты и остальные гидротехнические сооружения находятся в ведении ГП «Администрация 
речных портов Украины» с 2005 года, большая часть терминалов в частных руках. В перспективе ожидается развитие портов в рамках привлечения концессионеров, средств международных инвесторов и кредитов ЕБРР.

\section{Выводы и перспективы работы по данному направлению}

Современное состояние речной отрасли в целом позволяет справиться с существующими грузопотоками. Значительный рост объемов грузоперевозок возможен при одновременном разрешении нескольких разноплановых вопросов, в том числе и внеэкономического характера, а именно: корректировке искусственно заниженных железнодорожных тарифов, государственном дотировании речных перевозок на начальном этапе, производстве масштабных дноуглубительных работ, внесении кардинальных изменений в законодательство, касающихся регулирования речных перевозок, унификации правил пользования водными путями с европейскими, допуск иностранных участников на рынок услуг внутренних перевозок, привлечение инвестиций, модернизации ряда гидротехнических сооружений включая шлюзы, причалы и речные терминалы, заключение международных контрактов на поставки значительных объемов товаров. Суммарные вложения в отрасль оцениваются экспертами в миллиарды долларов США, ежегодная прибыль десятки миллионов. Низкая окупаемость означает малую привлекательность для инвесторов. Следует также учитывать лоббирование собственных интересов национальными финансово-промышленными группами.

Нестабильность украинской экономики, приближающиеся выборы, прогнозы мировых экспертов о возможности нового мирового кризиса, отсутствие перспектив привлечения серьезных финансовых средств дают возможность сделать вывод о том, что в ближайшие годы возможно лишь постепенное наращивание интенсивности речного судоходства в Украине, в основном за счет привлечения средств частного национального бизнеса. Значительное увеличение использования речного транспорта возможно в долгосрочной перспективе, при условии финансового участия государства в рамках реализации комплексного социального проекта.

\section{ЛИТЕРАТУРА}

1. Дойти до Роттердама: Зачем Франция строит канал Seine-North Europe [Электронный ресурс] / Т. Тавлуй // Центр Транспортных Стратегий. 2008. - - Режим доступа: https://cfts.org.ua/articles/doyti_do_rotterdama_zachem_frantsiya_stroit_kanal_ seine north europe $1403 / 100341$

2. Что ждет речной транспорт Украины в контексте евроинтеграции? [Электронный ресурс] / C. Кинка // Informer.Od.Ua/- 2016.- Режим доступа: http: //informer.od.ua/news/chto-zhdet-rechnoj-transport-ukrainy-v-konteksteevrointegratsii/

3. Внутренние водные пути Украины: пора возрождения [Электронный pecypc] / Н. Верещака / Порты Украины // № 03 (105) 2011. - Режим 
доступа к журн.: https://ports.com.ua/articles/archive/vnutrennie-vodnye-putiukrainy-pora-vozrozhdeniya

4. Куда ведет «Укрводшлях» - интервью и.о. начальника [Электронный pecypc] / А.Муравский // Порты Украины. - 2017.- Режим доступа к журн.: https://ports.com.ua/articles/kuda-vedet-ukrvodput-intervyu-io-nachalnika

5. О проекте Методики расчета ставок портовых сборов - вариант пятый [Электронный ресурс] / В. Попов / Моряк Украины.// № 3 от 24.01.2018. Режим доступа к журн.: https://moryakukrainy.livejournal.com/4202222.html

6. Закон о внутреннем водном транспорте: точки конфликта [Электронный pecypc] / А.Муравский // Порты Украины. - 2017.- Режим доступа к журн.: https://ports.com.ua/articles/zakon-o-vnutrennem-vodnom-transporte-tochkikonflikta

7. Деньги, шлюзы и закон: Как активизировать судоходство по Днепру [Электронный ресурс] / А. Костюченко // Центр Транспортных Стратегий.2018. - Режим доступа:

https://cfts.org.ua/articles/dengi_shlyuzy_i_zakon_kak_aktivizirovat_sudokhods tvo_po_dnepru_1391

8. Днепровские шлюзы [Электронный ресурс] / А.Д. Шершнев // Порты Украины. - 2018. - Режим доступа : https://ports.com.ua/spravka linfrastruktura/dneprovskie-shlyuzy

9. С караваном «НИБУЛОНа» - по Днепру через Каховский шлюз [Электронный ресурс] // Информационное агентство Інше.ТВ. -2017. Режим доступа: https://inshe.tv/video/2017-11-03/279042/

10. Речной торговый флот Украины за 30 лет сократился на $80 \%$ [Электронный pecypc] //Пропозиція - Главный журнал по вопросам агробизнеса. - 2017. - Режим доступа: http://propozitsiya.com/richkovyytorgovelnyy-flot-ukrayiny-za-30-rokiv-skorotyvsya-na-80

11. Все "за", один "против": кому выгоден закон о речных перевозках [Электронный ресурс] / О. Быстрицкая // Центр Транспортных Стратегий.2018.- Режим доступа:.- https://cfts.org.ua/articles/vse_za_odin_protiv_komu_ vygoden zakon o rechnykh perevozkakh 1172 